\title{
Palate Neoplasm
}

National Cancer Institute

\section{Source}

National Cancer Institute. Palate Neoplasm. NCI Thesaurus. Code C4402.

A benign or malignant neoplasm that affects the hard palate, soft palate, or uvula. 